$\dagger$ Department of Zoology, University of Oxford, South Parks Road, Oxford OX1 3PS, UK

1. Jansen, R. P. S. \& de Boer, K. Mol. Cell. Endocrinol. 145, 81-88 (1998)

2. Baker, T. G. Proc. R. Soc. Lond. B 158, 417-433 (1963).

3. Tsafiri, A. \& Braw, R. H. Oxf. Surv. Reprod. Biol. 6, 226-265 (1984)

4. Lynch, M. Mol. Biol. Evol. 13, 209-220 (1996).

5. Corral-Debrinsky, M. et al. Nature Genet. 2, 324-329 (1992).

6. Stearns, S. C. in The Evolution of Sex and its Consequences (ed. Stearns, S. C.) 337-349 (Birkhauser, Basel, 1987).

7. Hauswirth, W. W. \& Laipis, P. J. Proc. Natl Acad. Sci. USA 79, 4686-4690 (1982).

8. Bergstrom, C. T. \& Pritchard, J. Genetics 149, 2135-2146 (1998).

9. Shimuzu, S., Narita, M. \& Tsujimoto, Y. Nature 399, 483-487 (1999).

10. Pagel, M. Zool. Scripta 26, 331-348 (1997).

11. Guraya, S. S. Biology of Ovarian Follicles in Mammals 268-273 (Springer, Berlin, 1985).

12. Mira, A. J. Theor. Biol. 194, 275-287 (1998).

13. Mendez de la Cruz, F. R. et al. Funct. Ecol. 7, 535-540 (1993).

\section{Compensation for wind drift by bumble-bees}

In his classic studies on honeybee navigation, von Frisch had to rely on qualitative visual observations of the bees' flight paths, but nevertheless reached the surprising conclusion that bees seem to anticipate lateral wind drift and compensate by flying in shallow curves on the upwind side of their intended tracks ${ }^{1,2}$. We have investigated wind compensation ${ }^{1-3}$ with much greater precision by using $\operatorname{radar}^{4,5}$ to record the flight trajectories of individual bumble-bees (Bombus terrestris L.) foraging over arable farmland ${ }^{6}$. Flights typically covered distances of 200 to 700 metres, but bees maintained direct routes between the forage areas and their nests, even in winds with a strong cross-track component. Some bees overcompensated slightly, as described by von Frisch, but most stayed on course by heading partly into the wind and moving obliquely over the ground.

How did the bumble-bees know how far to turn off course to achieve the correct track to their destinations? Several species of Hymenoptera are known to use a Sun compass for navigation ${ }^{1,8}$, and if, as seems likely, bumble-bees share this ability', we propose that a simple strategy to keep on track in cross-winds would be for them to adjust their headings until the direction of ground image movement over their retinae (the optical flow ${ }^{10}$ ) occurred at the angle relative to the Sun's azimuth that corresponded to their intended tracks. This mechanism of controlling track direction by direct comparison of two optical directional cues not subject to parallax does not require the bees to assess wind speed or direction, or to compute the combination of heading and air speed required to stay on track. Support for a mechanism based on optical flow comes from visual observations that honeybees flying over water begin to drift with the wind ${ }^{11}$.
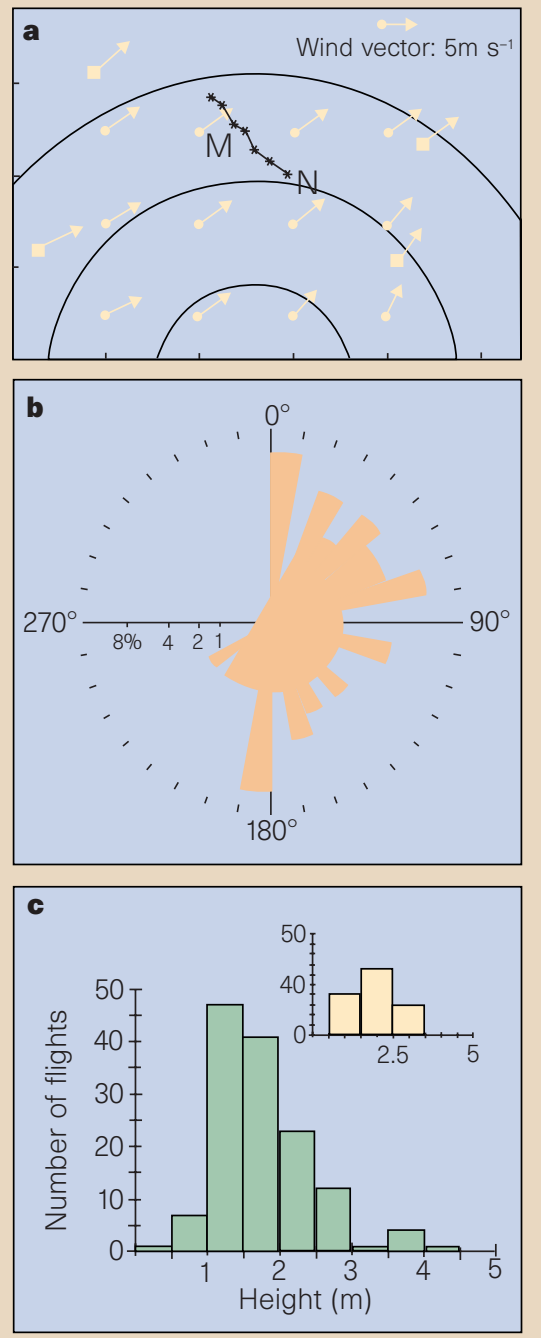

Figure 1a shows an example of crosswind flight compensation behaviour, which was typical of the 53 return flights examined (Fig. 1b). In still air (where air speed is the same as ground speed), the mean air speed of foragers was $7.1 \pm 0.43 \mathrm{~m} \mathrm{~s}^{-1}(n=8)$, and they flew about $2 \mathrm{~m}$ above the ground. In windier conditions, they flew lower on slow upwind tracks and higher in faster downwind movements (Fig. 1c, inset), as though they were adjusting their heights of flight to maintain a preferred rate of optical flow. Results from still air indicate that, if this were the case, the preferred rate for the visual field directly beneath the bees was about $7 \mathrm{~m} \mathrm{~s}^{-1} / 2 \mathrm{~m}=3.5 \mathrm{rad} \mathrm{s}^{-1}$. We therefore used this value to estimate the height of each flight (Fig. 1c), and subtracted the wind vector at this height from the bees' ground vector to yield air speed and heading.

The overall average air speed found in this way was $7.3 \pm 1.2 \mathrm{~m} \mathrm{~s}^{-1}$ (s.d.) $(n=74)$ in June, and $6.2=1.2 \mathrm{~m} \mathrm{~s}^{-1}(n=63)$ for July and August, and upwind flight was about $1 \mathrm{~m} \mathrm{~s}^{-1}$ faster than downwind flight in both study periods. The average air speed for June was greater than the fastest air speed $\left(7 \mathrm{~m} \mathrm{~s}^{-1}\right)$ predicted for bumble-bee
Figure 1 Estimation of air speed and heading. a, A bumble-bee approaching its nest $(\mathrm{N})$ on a crosswind flight trajectory; asterisks show its position at 3-s intervals. Radar range rings are $115 \mathrm{~m}$ apart. North is vertical. Squares are anemometry stations and arrows from them indicate the wind vector $2.7 \mathrm{~m}$ above the ground, averaged over the flight; arrows from circles indicate the windfield inferred by interpolation of these vectors. The vertical gradient of the wind speed up to $8 \mathrm{~m}$ above ground was measured by four anemometers on a mast $(M)$. From the ground speed we estimate that the bee flew about $2 \mathrm{~m}$ above ground level. Subtracting the wind vector at the track centre and at this height ( $3.8 \mathrm{~m} \mathrm{~s}^{-1}$ towards $54^{\circ}$ ) from the ground speed vector $\left(6.7 \mathrm{~m} \mathrm{~s}^{-1}\right.$ towards $\left.135^{\circ}\right)$ indicated that the bee's air speed was $7.2 \mathrm{~m} \mathrm{~s}^{-1}$, and its heading 167\%: it was laying off into the wind by $32^{\circ}$ from its homeward track. b, Circular histogram ${ }^{7}$ of $\theta=\mid$ track direction-wind direction| for bees flying on straight tracks directly to the nest (end-to-end distance/along-track distance $>0.85$ ), $n=53$. Radial scale shows the percentage of tracks falling within each $10^{\circ}$ bin, where $\theta=0^{\circ}$ corresponds to bees flying directly downwind; angles other than $0^{\circ}$ and $180^{\circ}$ indicate some cross-wind compensation. Wind speeds range from 0.6 to $7.2 \mathrm{~m} \mathrm{~s}^{-1}$. c, Distribution of flight heights, assuming that height=ground speed/3.5 for all flight trajectories $(n=137)$. The distribution is similar to that based on our visual assessment that upwind flights occurred between 0.5 and $1.5 \mathrm{~m}$, cross-wind between 1.5 and $2.5 \mathrm{~m}$, and downwind between 2.5 and $3.5 \mathrm{~m}$ (inset). This was not surprising, as our tower data showed that mean wind speed varied (as expected ${ }^{12}$ ) with the logarithm of height, so above $1 \mathrm{~m}$ it changed only gradually. The experiments were carried out in June and July/August 1996.

workers, implying a power output exceeding the $180 \mathrm{~W} \mathrm{~kg}^{-1}$ maximum currently attributed to bee flight muscle ${ }^{13}$.

J. R. Riley ${ }^{\star}$, D. R. Reynolds ${ }^{\star}$, A. D. Smith ${ }^{\star}$,

\section{A. S. Edwards $s^{\star}$, J. L. Osborne $\dagger$,}

I. H. Williams $\dagger$, H. A. McCartney $\dagger$

${ }^{*}$ NRI Radar Unit, University of Greenwich,

North Site, Leigh Sinton Road, Malvern,

Worcestershire WR14 1LL, UK

e-mail: jriley@nriradar.demon.co.uk

$\dagger$ Department of Entomology and Nematology,

IACR-Rothamsted, Harpenden,

Hertfordshire AL5 2JQ, UK

1. von Frisch, K. Dance Language and Orientation of Bees (Oxford Univ. Press, London, 1967).

2. von Frisch, K. \& Lindauer, M. Naturwissenschaften 42, 377-385 (1955).

3. Lindauer, M. in Insect Flight (ed. Rainey, R. C.) 199-216 (Blackwell, Oxford, 1976).

4. Riley, J. R. et al. Nature 379, 29-30 (1996).

5. Riley, J. R. et al. J. Insect Behav. 11, 287-296 (1998).

6. Osborne, J. L. et al. J. Appl. Ecol. (in the press).

7. Batschelet, E. Circular Statistics in Biology (Academic, London, 1981).

8. Wehner, R. Annu. Rev. Entomol. 29, 277-298 (1984).

9. Wellington, W. G. Science 183, 550-551 (1974).

10. Esch, H. E. \& Burns, J. E. J. Exp. Biol. 199, 155-162 (1996).

11. Heran, H. \& Lindauer, M. Z. Vergl. Physiol. 47, 39-55 (1963).

12. McCartney, H. A. \& Fitt, B. D. L. in Advances in Plant Pathology Vol. 3, Mathematical Modelling of Crop Disease (ed. Gilligan, C. A.) 107-143 (Academic, London, 1985).

13. Cooper, A. J. Thesis, Univ. Cambridge (1993). 